\title{
The School Adjustment of Sexual and Gender Minority Youths
}

\author{
Rho-tong Lee ${ }^{1, *}, \dagger$, Hong-ping $\mathrm{Qi}^{2, \dagger}$ \\ ${ }^{1}$ Chinese language and literature, School of Sichuan Normal University, Chengdu, Sichuan, 610066, China \\ ${ }^{2}$ School of Shanghai Experimental Foreign Language, Shanghai, 200093, China \\ *Corresponding author. Email: 20143353@stu.nun.edu.cn \\ Those authors contributed equally.
}

\begin{abstract}
School is the microcosm of society and is structured for students to obtain the necessary ability to adjust to society as an adult in advance. They are commonly encountering multiple difficulties. Also, in terms of sexual and gender minorities, their school adjustment would face more problems, which also makes their situations on campus tougher than most cis-heterosexual youths. Several influencing factors lead to bullying and violence against minorities by the majority in schools, which include the heterosexual hegemony culture, gender stereotyping, prejudice and stigmatization. In the context of school violence, emotional abuse, harassment, and negative school atmosphere, sexual and gender minority youths are prone to problematic behaviors and psychological issues and are faced with more obstacles in school adjustment, further leading to a vicious circle. This review systematically analyzes the problems encountered by sexual and gender minority youths in middle and high schools and proposes strategies and measures from various aspects, including society, family, and the media, to improve the school adjustment of sexual and gender minority youths.
\end{abstract}

Keywords: Sexual and Gender Minority Youths, School Adjustment, School Violence.

\section{INTRODUCTION}

Education is the reflection of society, which simulates society and replicates it in miniature [1]. As one of the main carriers of education, schools can reflect multiple societal issues. Sexual and gender minority is still a vulnerable group in society. Also, the adolescents among them are particularly worrying. Unfortunately, the tough situation of this group in the school circumstances has not received enough attention. In most middle and high schools, some sexual and gender minority adolescents choose to hide their sexual orientation and gender identity to avoid harassment, while others who have come out face difficulties in integrating into the mainstream group and bullying at school. Previous relevant studies generally focused on the school violence suffered by adolescents of sexual and gender minorities, which is one of the manifestations of the conflict between them and cisgender heterosexuality, while few studies focused on the adjustment issues of sexual and gender minority youths at school before and after they are under school violence. This paper is written to review the forms and difficulties of school adjustment for sexual and gender minority youths.

\section{THE TOUGH SITUATION}

Every individual is inevitably bound by mainstream ideas and group environment, whether they are in the society or the school-the miniature of the society. Widespread social violence against sexual and gender minorities also exists in middle and high school circumstances. In addition to the pressure and school violence, the cisgender heterosexuality is potentially faced with, for sexual and gender minority students, cisheterosexual hegemony culture, gender stereotypes, the stigmatization and prejudice against sexual orientation, and gender expression pressure which does not conform to the traditional gender norms and expectations are main factors that cause their struggling and negative attitudes towards schooling atmosphere and are detrimental to their identity and school adaptability [2]. 


\subsection{Cis-heteronormativity Pressure}

Under cis-heterosexual hegemony culture, students who do not conform to gender expectations and gender norms are marginalized and subjected to school violence and bullying. To avoid encountering conflicts with their peers, adolescents of sexual and gender minority group would deliberately hide their gender identity and sexual orientation and show behaviors consistent with the characteristics of cisgender heterosexuality, so as to cope with the social interaction on campus and try to integrate into the majority group.As a result, these minority adolescents would have anxiety about their own identity and worry that their true self can not be accepted by their peers and fall into a state of disunity.

\subsection{Misunderstanding and Stigmatization}

As for adolescents who come out at school, they have expressed their different sexual orientation and gender identity from the majority. Even if they are able to do so, it does not mean that their situation would be improved. People in different positions find it difficult to understand each other's situations, empathize with them or offer support. However, when the majority group is faced with the minority group, their privilege will prompt them to view the minority group in an unequal way and the misunderstanding and prejudice generated have a deep impact on the school and society adjustment of individuals in early adulthood, although this form of violence is invisible and often ignored[3]. Based on misunderstanding and prejudice, stigmatization of minority groups could spread and turn into physical violence. In the case of homophobia, heterosexual male students would deliberately express their masculinity by distancing themselves from gay students who they perceived as effeminate, or even harassing, verbally and physically abusing gay students in order to draw the line, which could lead to the internalized homophobia of gay students. Gay students are afraid to reveal their sexual orientation for fear of being seen as different and ashamed to ask for help, or even participate in bullying to protect themselves while hiding their sexual orientation. Similarly, lesbians are marginalized by female students. In addition, the awkward situation faced by lesbian students is mainly caused by heterosexual male students. The sexualization of lesbians and denial of the existence of this group are other means used by heterosexual men to to dispel their insecurities about their masculinity

\subsection{Behavioral and Psychological Issues}

Violence by majority groups against minority groups would lead to a negative school atmosphere, which further aggravate the occurrence of school violence and bullying [4]. The school atmosphere is invisible but extremely powerful. It exerts a subtle influence on the staff, teachers, and students in school. When the minority students feel others are rejected to socialise with them, minority students could easily feel that they have no possibility to become the participants of school life, becoming nobody but an outsider in school, such negative emotions, then, could lead to their psychological issues and problematic behaviors. Sexual and gender minority students may neglect self-care, develop self-loathing, self-harm and suicidal thoughts, which would affect their academic performance and school adjustment, trapped in a vicious cycle for lack of proper outside help.

\section{THE ATTEMPTS FOR ADJUSTMENT}

\subsection{Personal}

\subsubsection{Strengthen Self-protection}

Campus students are the subject of bullying. To prevent bullying, they should fully understand the seriousness of the consequences of school bullying, strengthen self-education and reflection, and learn to have the correct face of setbacks and failures. They should also develop a correct outlook on life and values, which can rationally treat others. It is also suggested for them to deal with problems, learn to control their emotions, and adjust their mentality to become calm with encountering problems.

\subsubsection{Improve Legal Knowledge}

Students' weak legal awareness is also an important reason for school bullying. Therefore, to avoid bullying, it is necessary to improve their legal literacy, read more legal books and information, to know the law from childhood. In daily study and life, to abide by the law, not only to respect the law of the country but also to learn to use the law to protect their security and rights and interests.

\subsection{School Aspect}

\subsubsection{Strengthen the Dissemination of Legal Knowledge}

Implementing legal education is an effective way to prevent school bullying. First, the school can offer courses on the law to enable students to develop an interest in legal learning. Secondly, the school can carry out legal knowledge contests, lectures, and other activities, to provide intuitive and vivid legal education. Finally, teachers can use multimedia courseware to play legal cases related to bullying, using practical case process to tell students how to better regulate their behaviors, avoid touching the legal minefield. 


\subsubsection{Pay Attention to Ideological and Moral Education}

For young students in today's society, it is very important to develop good behaviors habits and excellent moral character. First, the school should start from the classroom, such as requiring students to wear neatly, clean, meet teachers, answer questions, raise hands, follow the classroom rules, do a good review after class, good behaviors habits, and good moral habits, second, the school should be ideological and moral education knowledge in the knowledge of students to learn, so that the ideological and moral education becomes more vivid, vivid, which should be more than the boring indoctrination education can arouse students 'interest, and better arouse ideological resonance for students to understand and master; Finally, the school should conduct some activities, competitions or expert lectures on ideological and moral education, pay more direct attention to students' ideological and moral education, to prevent some bad behaviors.

\subsubsection{Formulate Emergency Plans}

Once bullying occurs, the consequences will be very serious, so efforts should be made to handle the followup treatment of bullying incidents and later prevention work. The campus should establish a working system to prevent and control student bullying and violence, and incorporate it into the overall consideration of school safety work. To better prevent and control the occurrence of school bullying, we should make emergency plans in advance. On-campus, the school should pay attention to cultivate teachers and students' legal concepts and legal knowledge teaching, enhance their legal awareness and self-protection awareness; the school should install indoor and outdoor surveillance video equipment, timely grasp the dynamics on campus, to prevent violence Students; arrange a daily inspection on duty and implement the duty management responsibility system.

\subsection{Family}

\subsubsection{Create a Good Family Atmosphere}

A good family atmosphere has a great role in students' psychological and physiological growth. A good family atmosphere also helps children stay away from violence. Family members should face children, do not lose their temper to the child, or time will encourage children, affirm their small achievements in some aspects; to learn to appreciate children, praise the child, find the shining point, more praise, less dissatisfaction; the child as a family center, parents should give the child enough voice, to be democratic, and willing to listen to happiness and troubles; if the child meets To what difficulties, do not care, should be given certain attention, for the child to consider comprehensive, remember not to ask.

\subsubsection{Improve the Moral Quality of Parents}

Parent behaviors are to give their children the most direct example. Therefore, parents should set an example, improve their ideological and moral quality, and do a good example for their children. First, parents promise their children to do, speak and consider the feelings of children, second, establish the concept that the child is the future of the motherland, the best to educate their children; moreover, parents must have certain scientific and cultural knowledge, the higher the parent knowledge level, the more conducive to family education; finally, parents should have the correct outlook on life and value view that correctly guide children to understand school bullying, to avoid the occurrence of school bullying incidents.

\subsection{Social}

\subsubsection{Strengthen Media Publicity}

Society should strengthen the publicity of the serious consequences of school bullying, which can not only make students fully realize the seriousness of the consequences and stay away from violence but also help strengthen the school staff's understanding of school bullying, to better prevent and supervise school bullying. In addition, we should use the power of the media to publicize some positive news and cases around us, so that students can deeply feel the seriousness of the consequences of violence; we can also use the media to do some special columns on youth education management to prevent experts and professors from explaining how to prevent bullying, How to better deal with the incident, and to guide the students, parents and the school respectively, to better prevent the occurrence of violence.

\subsubsection{Improve the Environment Around the Campus}

Relevant social departments should step up efforts to rectify the surrounding environment of the school and the campus to provide a safe and comfortable place for students to study. It is strictly stipulated that Internet cafes, game halls, and other entertainment places are not allowed near schools; some small vendors staying at or around the school are forbidden to sell various food and goods. Reasonable and strict management of the surrounding environment is one of the effective measures to prevent and control school bullying. Because of the chaotic environment around the school, illegal vendors, and inadequate management of relevant departments, all sectors of society should strengthen 
supervision, put an end to any school bullying in daily management and be students The physical and mental health escort, to provide a healthy and pure learning place for campus students.

\section{THE FAILURE AND STRATEGIES}

\subsection{Weak Ideology}

Due to the rapid development and popularization of the Internet, some violence and other unsafe factors such as pornography have also begun to revolve around people, especially with the biggest adverse impact on on-campus students. They browse a lot of bad information through computers and mobile phone clients, which is undoubtedly a great psychological impact for campus students who cannot accurately perceive the quality of things and have a weak ideology. The author once interviewed the internship instructor. She said in the interview: 612-year-old children are in an ignorant youth. Although they have not become adults, they fantasize that they become adults, so they began to learn the violence of browsing online behaviors, thus highlighting their growth. It is precisely because of the fragile psychological defense line and insufficient ideological consciousness, which leads to the continuous occurrence of violent incidents.

\subsection{Lack of Parental Sense of Responsibility}

A good family environment is very helpful to the child's psychological growth, behaviors, and character formation; on the contrary, a bad family environment will have a bad impact on many aspects of the child, making the child's psychology, behaviors, personality, and other aspects of abnormal behaviors.

Families do not guide children or develop selfdiscipline and self-loving families, parents do not teach their children the correct outlook on life and values, nor urge them to develop good life and learning habits, which can be serious; single-parent children may also have an unhappy family life and feel that parents do not care enough, causing violence towards others and embark on the road of crime.

\subsection{Imperfect Moral Education}

Due to the particularity of the subject and place of school bullying incidents, such incidents once became the top priority of social and legal management. From the perspective of management, the school's supervision and prevention of school bullying are not in place, does not fail to stop the violence in time, and does not deal with it well afterward, which will lead to the deterioration of school bullying and cannot be properly ended. From the perspective of moral education, in current society, especially on the campus, is quite imperfect and not in place, and teachers' moral education for students is also a face project and did not fully penetrate the moral education thought into the children's study and life, let alone Talk about letting students use moral education to strengthen their selfeducation.

School moral education blindly carries out indoctrination education, does not give full play to students' initiative of students, only cares about the teaching of book knowledge, cannot make moral education knowledge deeply rooted in the hearts of the people.

\subsection{The Spread of Bad Social Atmosphere}

There are many reasons for the frequent school bullying incidents, and the spread of a bad social atmosphere is one of the important reasons. The rapid development of today's society has led to the large gap between the rich and the poor and the uneven distribution of wealth. The blind worship of money and wealth enables some students to achieve their purpose by bullying others. Therefore, the spread of a bad social atmosphere has strengthened the awareness of bullying among campus students, which makes campus students who want to achieve some purpose subconsciously use violence in handling some things. Therefore, school bullying incidents have become more and more intense under the influence of a bad social atmosphere.

\section{CONCLUSION}

Heterosexual and cisgender hegemony and oppression of sexual and gender minority youths do exist in schools, and the adjustment of sexual and gender minorities to schools is related to the social maladjustment of sexual minorities of all age groups, which is a widespread and urgent problem to be solved. In the school life experienced by sexual and gender minority youths, they will face the difficult situation that the mainstream group is not capable of imagining, and the conflicts between students of different sexual orientations and sexual identities and cisgender heterosexuality are also inevitable. Sexual and gender minority youths struggle with self-identity and integration into the majority, yet few people can notice and help them. After reviewing previous research and analyzing the problem of maladjustment of sexual and gender minority youths, we found that the improvement strategies to the school adjustment of sexual and gender minority youths cannot be limited to one aspect, because the factors leading to their situation are extremely complex and multifaceted, and it is a concerted effort of all communities, with families, schools and the media all bearing the responsibility. 


\section{REFERENCES}

[1] É. Durkheim (2006), On Suicide, first ed., Penguin Books, London.

[2] S. T. Russell, Beyond Risk: Resilience in the Lives of Sexual Minority Youth, J. Gay Lesb Issue Educ. (2005), 5-18.

[3] T. Lea, J. De Wit \& R. Reynolds, Minority Stress in Lesbian, Gay, and Bisexual Young Adults in Australia: Associations with Psychological Distress, Suicidality, and Substance Use, J. Arch Sex Behav. (2014)1571-1578.

[4] V. P. Poteat, D. L. Espelage \& B. W. Koenig , Willingness to Remain Friends and Attend School with Lesbian and Gay Peers: Relational Expressions of Prejudice among Heterosexual Youth, J. Youth Adoles . (2009) 952-962.

[5] A. Vaccaro, Campus Microclimates for LGBT Faculty, Staff, and Students: An Exploration of the Intersections of Social Identity and Campus Roles, J. Journal of Students Affairs Research and Practice. (2012) 429-446.

[6] M. L. Leah, J. W. Ryan \& M. P. Rebecca, Biasbased Bullying and School Adjustment among Sexual and Gender Minority Adolescents: the Role of Gay-straight Alliances, J. Journal of Youth and Adolescence. (2020)1094-1109.

[7] J. E. Willie, Operating within the Mainstream: Coping and Adjustment among A Sample of Homosexual Youths, J. Deviant Behavior. (1996) 229-251.

[8] H. M. Kenneth, G. Robert \& J. M. Harvey, Promoting the Successful Development of Sexual and Gender Minority Youths, J. American Journal of Public Health. (2014)976-981.

[9] L. R. Sari, A. G. Emily, T. P. Jeffrey \& L. Y. Michele., Gender Minority Social Stress in Adolescence: Disparities in Adolescent Bullying and Substance Use by Gender Identity, J. The Journal of Sex Research. (2015)243-256.

[10] C. Sharon, E. E James \& W. S. C. Robert., School Climate \& Sexual and Gender Minority Adolescent Mental Health, J. Journal of Youth and Adolescence. (2019)1938-1951.

[11] J. D. Willie. The Prevention and Treatment of Campus Violence from the View of Criminology. Law Forum, 2019, pp. 87-95.

[12] J.Y. Abboot. "School violence" with "school bullying" concept reshaping. Juvenile Crime Issues, 2018, pp. 44-52.
[13] J. D. Alexxan. "School Bullying": Connotation identification, application limit and redefinition. Education Development Research, 2018, pp. 26-33.

[14] H. E. WillieAlva. Comparative Study of American Campus Violence Crimes-Investigation and Analysis Based on 94 Typical Cases. Journal of Renmin Public Security University of China (Social Sciences Edition), 2017, pp. 1-18.

[15] J.D Coboo. The - of the prevention and control of campus violence takes the "malicious age" rule as the entry point. Social Science of China, 2017, pp. 93-101.

[16] L. R.Alvian. The conceptual definition of "school bullying" and its legal responsibility. Proceedings of East China Normal University (Education Science Edition), 2017, pp. 43-50.

[17] L. B.Wolly. The Interdisciplinary Dialogue on School Bullying Governance. Proceedings of East China Normal University (Education Science Edition), 2017, pp.12-23.

[18] Q.W Luxio. Current Situation and Countermeasures of Juvenile Campus Violence in China. Chinese Youth Studies, 2017, pp. 100-104.

[19] S.N. Sonui. Research on Campus Violence Prevention from the View of National Governance. Chinese Youth Social Sciences, 2017, pp.26-33.

[20] A. G. Zoey. Comparative Study on American School Bullying Prevention and Control. Central China Normal University, 2016.

[21] J. E. Puppyoy. Current Research on Campus Violence and Preventive Countermeasures for Middle School Students in China. Central China Normal University, 2016.

[22] Z. D. Zoppy. Comparative Study on Campus Violence Legal Regulation in China. Youth Studies, 2016, pp.16-22.

[22] J. E. Lkuan. Current Situation and Preventive Countermeasures of Campus Violence in Chinese Middle School. Hebei Normal University, 2015. 